IMAGINARIO COLECTIVO MUSICAL

\section{Convenciones en el proceso de interpretación del sentido de la música}

\section{Eddy L. Borges Rey}

\section{Profesor e investigador}

Facultad de Ciencias de la Comunicación. Universidad de Málaga. Campus de Teatinos, 29071 Málaga (España). Email: eborgesrey@uma.es

\section{Resumen}

La sociedad humana se ha construido a sí misma con el pasar de los años. A cada nueva revolución de pensamiento, los modelos sociales se han modificado; como resultado, los procesos que tenían como finalidad establecer los cimientos de una red de relaciones de todo ámbito desembocaron en aquello que los seres humanos percibimos en la actualidad como nuestro entorno.

Sin embargo, no sólo se ha construido aquello que se aprecia a simple vista, sino también otras complejas abstracciones que han pasado desapercibidas pero que dan sentido de manera tácita a numerosos elementos del vivir cotidiano. A nuestro alrededor, miles de signos son interpretados a velocidades inimaginables. Sobre esos sistemas de
Palabras clave

Semántica musical, Música y Sociedad,

Música y Comunicación,

Imaginario colectivo musical

Key Words

Musical Semantics, Music and Society, Music and Communication, Collective Musical Imaginary

\footnotetext{
Abstract

Human society has built itself over the years. Social models have been trans-

formed with each new revolution of thinking; those processes, which served the purpose of settling the foundations for a net of relations in every field, led to what we human beings nowadays perceive as our environment.

However, not only what is visible at first glance has been built, but also unnoticed, complex abstractions which tacitly give a meaning to numerous elements of everyday life. Many situations happen around us in which thousands of signs are interpreted at an unimaginable speed; it's on these signification systems that conventions are constantly rewritten in a perpetual code update.

This is how music in particular stands out as a form of discourse that generates an interpretation. From the study of significance's point of view, music provokes a response on the receiving end, but the answer to how that response is generated is still an issue for heated, passionate discussions among
} experts. 
significación se reescriben las convenciones en una eterna actualización de códigos.

Es así como llama la atención en particular el caso de la música como discurso que genera una interpretación. Desde la óptica del estudio del significado, la música despierta una respuesta en la dimensión encargada de comprenderla, pero el cómo se genera esa respuesta sigue siendo objeto de acaloradas y apasionadas discusiones entre los teóricos.

La intrincada relación de conceptos generados y reforzados en el tiempo por medio de la interacción social construyen nuestra interpretación musical. Por ello, y para comprender en su totalidad el proceso, repasaremos estudios como el de "Social Constructionism", enfoques cognitivos, Generativismo, Social Representation o Interaccionismo Simbólico para enmarcarlos en el campo de la experiencia de la música y acercarnos a la comprensión del fenómeno del imaginario colectivo musical.

The intrincate relations among generated concepts -reinforced in time by social interaction- build our musical interpretation. This, in order to understand the process in its entirety, we will review studies such as Social

Constructionism, cognitive approaches, Generativism, Social Representation, and Symbolic Interactionism, in order to enclose them into the musical field and get to the comprehension of the collective musical imaginary phenomenon.

\section{Introducción}

Tras años en los que el conocimiento generado en torno a la reflexión sobre la música se había mantenido circunscrito a los conservatorios y escuelas de interpretación musical, una serie de disciplinas vinculadas al ámbito social (psicología, sociología, ciencias de la comunicación, filosofía, etnografía, etc.) encontraron un asidero a la hora de explorar un fenómeno que, por causa mayor, debía ser contemplado desde la perspectiva de su relación con el hombre y la sociedad. Cuando esto ocurre, el panorama del estudio de la música comienza a ampliarse: no sólo se abre a géneros musicales relegados hasta entonces por el estudio artístico, también se incrementa el interés hacia fenómenos como la tecnología, la industria musical y la audiencia.
Así, se consolidan innovadoras teorías que favorecen el establecimiento de nuevas disciplinas relacionadas íntegramente con la música. Una de las corrientes más asentadas hoy en día es la del estudio de la música popular. Es en ella donde se evidencia de manera más rotunda la mencionada ampliación del espectro. Los textos publicados desde el nacimiento de las corrientes sociales de la música reflejan la riqueza de contenido existente en el seno de la sociedad industrializada y mediatizada- de nuestra época. Sobre esta relación entre música e individuo, Frith expone: "La cuestión que debemos responder no es qué revela la música popular sobre los individuos sino cómo ésta música los construye." (Frith, 2001, 418) 


\section{Objetivos}

Los planteamientos que dieron origen a estas reflexiones se orientan inicialmente hacia la cuestión del significado de la música. A este respecto, se trata de obtener respuesta a los siguientes interrogantes: ¿Es arbitraria la relación entre música y significado? ¿Se puede postular una unidad compleja y no excluyente en las teorías sobre producción del sentido de la música? ¿Son los procesos imaginarios de los autores e industrias musicales los que dictan las pautas de interpretación del sentido de las músicas? Sobre este eje conceptual se establece una serie de objetivos:

1. Catalogar y sistematizar una muestra teórica sobre la relación músicahombre.

2. Extraer teorías y postulados de diferentes disciplinas.

3. Relacionar éstas teorías y postulados a fin de obtener criterios y conceptos no excluyentes.

4. Interpretar la relación de los nuevos conceptos en el campo de aplicación.

\section{Metodología}

Tomando como punto de partida una exploración teórica de las principales corrientes relacionadas con la construcción y la representación social, memoria colectiva, semántica generativa, etc., el segundo paso consiste en relacionarlas con experiencias y documentos recogidos por diferentes tradiciones y disciplinas académicas de inclina- ción social como lo son la musicoterapia, rasa hindú, psicología congnitiva y música, etnomusicología, antropología musical, música y comunicación, etc. Finalmente se esbozan aproximaciones e inferencias basamentadas en la triangulación y confrontación de teorías.

\section{Lo etéreo en la música}

Al abordar una exploración crítica acerca de las principales teorías que deducen supuestos en el campo de la significación musical, resulta evidente que la mayoría de los investigadores que se encuentran tras ellas transitan por caminos muy similares.
Las preguntas y las respuestas se repiten en una red de conceptos sin orden aparente. Se concibe una estructura en las formas musicales, se percibe un mensaje tácito, se atribuye la naturaleza de este mensaje a cuestiones puramente psicológicas, sociales 
o culturales. Se habla de manera común del fenómeno comunicativo musical. Se observa en el sonido una cualidad de signo. Pero una vez justificados los postulados, el modelo queda desdibujado por falta de rigor y formalidad.

$Y$ es que en la música operan relaciones que se encuentran en niveles de realidad tan dispares y poco conciliables que los esfuerzos de los estudiosos de la música han dado como resultado la parcelación del conocimiento, ofreciendo pocas esperanzas de llegar a una unificación de criterios.

Al final, la mayoría se disgrega: hacia el estudio del código o notación musical; hacia la incidencia de la música en los colectivos sociales; hacia el efecto de los estímulos sonoros en la psique humana... Todo ello sin percibir que precisamente en la unión y organización de todos estos fenómenos, aislados a la fuerza, está la valiosa respuesta a la pregunta: ¿Cómo interpreta el ser humano un mensaje en la música y genera una respuesta?

Pousseur, en su obra Música, semántica, sociedad, plantea en su segmento introductorio un interrogante que se cita a continuación:

Una vez que las diversas formas sonoras se han percibido de forma repetida, una vez distinguidas entre sí, agrupadas en clases con ciertas propiedades comunes y pudiendo ser articuladas entre sí de manera "económica”, llegan a constituir todo un vocabulario más o menos diferenciado y susceptible de elaboración. El campo de las onomatopeyas al cual, movidos por una necesidad de expresión con imágenes, han recurrido tan a menudo nuestros lenguajes para revitalizarse es, sin duda, si no el mejor, sí al menos el primer ejemplo de una recuperación de elementos por parte del primer grupo fenoménico considerado, encontrados primeramente en los otros grupos. ¿Podríamos preguntarnos si una recuperación similar se produce dentro del ámbito específicamente musical? (Pousseur, 1984, 11).

A esta pregunta ambiciosa, que muchos eruditos de la música se hacen, no se halla una respuesta satisfactoria.

Y es que el tema de la significación musical genera una polémica exacerbada. La músi$\mathrm{ca}$, por naturaleza, representa contradicciones de todo orden. Así, las disciplinas que la estudian desde ópticas diferentes adoptan una actitud cada vez más excluyente. Durante décadas, y antes de la consolidación del estudio social de la música, el universo de documentos redactados sobre el estudio de la música provenía de la tradición de los conservatorios y se caracterizaba por la falta de formalidad científica en la comprensión de un objeto que, desde su perspectiva, era etéreo y delicado. Considerando además que el estudio de la música es relativamente joven en el campo del conocimiento y de la ciencia, es casi seguro que su carácter 'emocional' lo seguirá colocando en el centro de numerosas controversias durante algunos años. 
No se pretende en esta introducción alarmar ni desmerecer esfuerzos anteriores que han arrojado mucha luz sobre este tema: estudios como los de Meyer en el campo de la significación musical (en los que empleó principios de la Gestalt a la hora de abordar el proceso de interpretación musical), u otros fundamentales como el de Storr (que transita entre la música y los complejos procesos mentales, profundizando en las emociones como respuesta al mensaje musical) son obras que deben ser tomadas como punto de partida para una comprensión más amplia de la música. Asimismo, las aportaciones realizadas desde la perspectiva semiótica, así como las de la escuela francesa de los estudios cognitivomusicales, deben considerarse nociones elementales de la materia.

Finalmente, un campo en apariencia relegado por sus complejos niveles de abstracción es el de los imaginarios sociales relacionados con la música. A este respecto, la obra de Berger y Luckmann, contenida inicialmente en su importante Construcción social de la realidad, representa un pilar fundamental y un punto de partida en este área de estudio. Posteriormente, Cook mencionaría estos elementos imaginarios en muchas de sus obras y los relacionaría con la significación de la música, haciendo contribuciones de importancia.

Profundizar en este campo es el objetivo fundamental del presente estudio. Haremos inicialmente un recorrido teórico por las corrientes que estudian las representaciones sociales, la construcción social del conocimiento, la inteligencia y la realidad, los elementos de la interacción social y comunicativa, el construccionismo y los imaginarios colectivos entre otros para, finalmente, aproximarnos desde estas perspectivas a la música, haciendo hincapié en la generación de imaginarios musicales y, por ende, la institucionalización de convenciones semánticas en la comunicación musical.

\section{La realidad social y sus colectivos}

Todo el repaso teórico que veremos a continuación no tiene una aparente relación con la música, ya que estos postulados han sido concebidos para explicar la forma en la que las sociedades construyen su realidad o los colectivos generan sus acervos de conocimiento.

Como ya sabemos, las sociedades y los entornos colectivos desarrollan a través de sus prácticas una gran cantidad de fenómenos, por medio de los cuales crean no sólo sus mecánicas de interacción y comunicación, sino valores fundamentales, como los morales, los ideológicos y los culturales. No es sino a través de estas relaciones mutuas que se construye la realidad que nos rodea como individuos pertenecientes a 
grupos y a macrocolectivos socialmente organizados.

Stangor, en una cita de Moscovici, el padre de la Social Representation, expone una cuestión fundamental que podría servir como punto de partida al planteamiento aquí expuesto: "Cultures are defined in large part by the common beliefs held by their members. But we have not yet been very specific about how those beliefs develop or what they really refer to" (Stangor, 2004, 273), lo que evidencia un vacío en la comprensión del fenómeno de la construcción social.

A mediados del siglo pasado, Berger y Luckmann desarrollaron una teoría de gran valor que explica la cuestión de Moscovici (más adelante nos extenderemos en la respuesta particular de Moscovici a su pregunta) y que instaura los cimientos de una corriente que, con el pasar de los años, se denominará Social Constructonism.

Burr revisa en su obra los planteamientos de los autores y explica de manera condensada la esencia de su trabajo:

“Berger and Luckmann's anti-essencialist account of social life, argues that human beings together create an then sustain all social phenomena through social practices. They see three fundamental processes as responsable for this: externalisation, objectivation and internalisation” (Burr, 2003, 13).

De hecho, Berger y Luckmann establecen varios niveles de legitimación e institucio- nalización de los valores sociales a la hora de construir la realidad del entorno. Como explican en su obra: "La realidad social de la vida cotidiana es, pues, aprehendida en un continuum de tipificaciones que se vuelven progresivamente anónimas a medida que se alejan del 'aquí y ahora', de la situación 'cara a cara'" (Berger y Luckmann, 1995, 51), explicando cómo una habitualización individual puede tornarse paulatinamente social y, finalmente, convertirse en conocimiento.

Los autores hablan de dos dimensiones, la de la institucionalización que tiene lugar en un pequeño colectivo y la de la legitimación que convierte ese valor institucional en un conocimiento social. En primer lugar, nos detendremos en el proceso de legitimación y lo estudiaremos grosso modo. En palabras de los autores: "Toda actividad humana está sujeta a la habituación. Todo acto que se repite con frecuencia crea una pauta que luego puede reproducirse con economía de esfuerzos y que ipso facto es aprehendida como pauta por el que la ejecuta” (Berger y Luckmann, 1995, 74). Es así como esta habituación genera a nivel individual un sistema de pautas preestablecidas, que posteriormente crean un "depósito general de conocimiento" en ese mismo individuo: "Las acciones habitualizadas retienen, por supuesto, su carácter significativo para el individuo, aunque los significados que entrañan llegan a incrustarse como rutinas en su depósito general de conocimiento que da por establecido y que 
tiene a su alcance para proyectos futuros" (Berger y Luckmann, 1995, 74).

Recalcan además que los procesos de habituación anteceden a cualquier proceso de institucionalización y que ocurren a nivel del individuo. Es así como cualquier compositor puede crear la carga semántica que considere adecuada para cualquier construcción discursiva a un nivel íntimo.

Una acción habitualizada se institucionaliza cuando se da una tipificación recíproca de dicha acción por parte de diferentes actores. Este proceso debe ser continuo: "Las tipificaciones recíprocas de acciones se construyen en el curso de una historia compartida: no pueden crearse en un instante" (Berger y Luckmann, 1995, 76).

Tras el proceso de institucionalización a través de esa historia compartida, se inicia lo que Berger y Luckmann denominaron sedimentación intersubjetiva, que en el caso de la música ocurre cuando “(...) varios individuos comparten una biografía común, cuyas experiencias se incorporan a un depósito común de conocimiento" (Berger y Luckmann, 1995, 91). La sedimentación intersubjetiva sólo puede considerarse verdaderamente social cuando se ha objetivado en cualquier sistema de signos, esto es, cuando surge la posibilidad de objetivaciones reiteradas de las experiencias compartidas. Sólo entonces hay posibilidad de que esas experiencias se transmitan de generación en generación y de una colectividad a otra.
Es así como entramos en el plano de la legitimación que “(..) explica el orden institucional atribuyendo validez cognoscitiva a sus significados objetivados”. O, explicado de otra manera, que justifica el orden institucional adjudicando dignidad normativa a sus imperativos prácticos. Este proceso ocurre básicamente en cuatro niveles:

(...) la legitimación incipiente aparece tan pronto como se transmite un sistema de objetivaciones lingüisticas de la experiencia humana. (...) el segundo nivel de legitimación contiene proposiciones teóricas en forma rudimentaria. (...) El tercer nivel de legitimación contiene teorías explícitas por las que un sector institucional se legitima en términos de un cuerpo de conocimiento diferenciado y finalmente (...) Los universos simbólicos constituyen el cuarto nivel de legitimación (...) Se concibe como la matriz de todos los significados objetivados socialmente $y$ subjetivamente reales (Berger y Luckmann, 1995, 122-125).

Es así como finalmente un conocimiento se legitima ante la sociedad y se convierte en uno más de los postulados que integran el marco de conocimiento de las sociedades. Pero, ¿a través de qué medio se genera todo este proceso?

Los construccionistas ven en el lenguaje -y, más específicamente, en el discurso- una forma de interactuar entre los individuos para generar los procesos de institucionalización antes mencionados. "Language produces and constructs our experience of 
each other and ourselves (...) It provides us with a system of categories for dividing up our experience and giving it meaning" (Burr, 2003, 62).

En esta constante búsqueda de significados se centra nuestra razón de ser y de vivir, al tiempo que se consolida nuestra experiencia individual y nuestra cultura como colectivo. Pero al referirnos al lenguaje no sólo tomamos en consideración el habla o la escritura, como suele ser característico.

Whereas discursive psychology seems to emphasize the freedom of the speaker to draw upon a language as a cultural resource for his or her own end, macro constructionism emphasizes the way that the forms of languages available to us set limits upon, or at least strongly channel, not only what we can think and say, but also what we can do or what can be done for us. The use of the term "discourse" here, then, incorporates not just language but practice, too (Burr, 2003, 63).

Esta visión del discurso como una práctica social nos permitirá más adelante clarificar el enfoque de la música como discurso y, por tanto, como construcción social. Burr enfatiza la importancia del discurso como canalizador y catalizador de prácticas que serán posteriormente institucionalizadas y conformarán el continuum de conocimientos al que hacían referencia Berger y Luckmann en su obra.

El ser humano no sólo se comunica en su entorno social mediante de las palabras que emite a través de su aparato fonológico, sino que, a su vez, relaciona ésto -que denominamos habla- y lo articula con gestos, vestimentas, pertenencia a determinados colectivos, ideologías, etc., que conforman un discurso mucho más rico en contenidos. Burr complementa esta idea al agregar que "All the objects of our consciousness, every "thing" we think of our talk about, including our identities, ourselves, is constructed through language, manufactered out of discourses (...) A discourse provides a frame of reference, a way to interpreting the world and giving it meaning that allows some objects to take shape" (Burr, 2003, 105).

Es por esta razón que los construccionistas ven en la interacción social una fuente fértil de cuestionamientos constantes que van generando postulados, que a su vez son tomados por los colectivos como discursos propios. "It is through the daily interactions between people in the course of social life that our version of knowledge become fabricated" (Burr, 2003, 4). Esta aseveración es reafirmada por Alfred Schutz en su teoría sobre la adquisición del conocimiento.

Schutz hace alusión a las practicas "habitualizadas” de Berger y Luckmann, pero las denomina "tipificaciones y recetas". Explica que "el hombre, desde su nacimiento, comienza a disponer de una serie de tipificaciones y de recetas, de conocimientos y de modos de aplicación de esos conocimientos. Este proceso de adquisición es 
acumulativo. Estos conocimientos y su forma de aplicación están expresados bajo la forma de tipificaciones y recetas, y constituyen el acervo común de conocimiento, la cultura” (Camero Rioja, 2002, 101).

Este caudal de conocimiento también fue mencionado por los constructivistas como "depósito general de conocimiento", así que la idea del imaginario comienza a ser "habituada". Poco a poco se institucionalizará.

Camero Rioja, citando a Schutz, plantea un paisaje interesante sobre el meollo de la construcción del conocimiento:

Nuestro mundo cotidiano es desde el comienzo un mundo intersubjetivo de cultura. Es intersubjetivo porque vivimos en él como hombres entre otros hombres, ligados a ellos por influencias $y$ trabajos comunes, comprendiendo a otros y siendo un objeto de comprensión para otros. Es un mundo de cultura porque, desde el comienzo, el mundo de la vida es un universo de significación para nosotros, es decir, una estructura de sentido que debemos interpretar, $y$ de interrelaciones de sentido que intuimos sólo mediante nuestra acción en este mundo de la vida. Es también un mundo de cultura porque somos siempre conscientes de su historicidad, que encontramos en la tradición y los hábitos, y que es posible examinar porque lo "ya dado" se refiere a la propia actividad o a la actividad de otros, de la cual es el sedimento" (Camero Rioja, 2002, 99-100).
Al resaltar la importancia de las estructuras de significación, le damos a esos significados inmersos en todo una dimensión más trascendente. No es sino a través de las interacciones discursivas y los significados que procesamos que nos identificamos con las "verdades" propuestas por algunos, y esas "verdades" terminan siendo institucionalizadas en un patrimonio general del conocimiento. "Por supuesto que existen algunos objetos comunes $y$, por tanto, algunos valores comunes, valores a los que los sujetos otorgan un mismo significado, significados que han sido construidos a partir de un proceso de identificaciones mutuas" (Camero Rioja, 2002, 93).

A medida que caminamos entre corrientes y teoricos, constatamos que conceptos y definiciones se reiteran en una idea general. Camero Rioja revisa también a un teórico de importancia innegable en lo concerniente a institucionalización de conocimiento. Blumer, el padre del interaccionismo simbólico, expone su planteamiento recalcando inicialmente la importancia de la interacción: "La interacción modela nuestra capacidad de pensamiento al tiempo que la capacidad de pensamiento da forma a la interacción. Sólo la interacción simbólica, aquella que necesita de la interpretación del acto, implica pensamiento" (Camero Rioja, 2002, 88).

Blumer explica que "el significado de los objetos no reside en ellos ni es una cualidad de los mismos, sino que "el significado de estas cosas deriva de, o surge como conse- 
cuencia de, la interacción social que cada cual mantiene con el prójimo. Los individuos aprenden el significado de los objetos (...) en la interacción, y, puesto que las interacciones son diferentes, los significados de los principios también lo serán. El significado que una cosa encierra para una persona es el resultado de las distintas formas en que otras personas actúan hacia ella en relación con esa cosa" (Camero Rioja, 2002, 90). En suma, el significado es un producto social, lo que más adelante será puesto en tela de juicio por el generativismo de Chomsky, que se explorará en su momento.

Uno de los aspectos importantes de Blumer y su obra es que comienza a exponer la reciprocidad, que será caracterl̀stica del proceso generativo del imaginario y su colectivo. Al estilo del huevo y la gallina, Blumer resalta que la interacción modela el pensamiento $\mathrm{y}$, a su vez, el pensamiento modela la interacción, un planteamiento que establece la esencia de la Social Representation de Moscovici. De hecho, expone:

Representations theory assumes, in fact, that "there is no brake between the exterior universe and interior universe of the individual (or the group). The subject and the object are not fundamentally distinct" (Moscovici, 1969, p. 9). The object is scribed in an active context. And the context is at least partially conceived by the person or the group as a continuation of the behavior, the attitudes, and the norms it refers to. (...) We will argue that there is no priori objective reality, but that all reality is represented. By this we mean to say that reality is appropriated by the individuals (or the group), reconstructed in their cognitive system, and integrated in their value system. This processes in turn depend both on their history as well as on the social and ideological context surrounding the individual or the group (Deaux, y otros, 2001, 42).

La pregunta inicial de Moscovici que hicimos para introducir el Social Constructionism tiene una respuesta propia en el campo de la representación social : "One way to think about the beliefs that hold a culture together is to consider them in terms of social representations (Moscovici, 1988). A social representation is a pattern of beliefs, values, norms and practices that are shared by the members of a culture and that provide meaning for the culture" (Stangor, 2004, 273).

La Social Representation tiene su visión sobre el proceso de generación de los imaginarios colectivos, esta vez con la mención de los medios de difusión masivos como un catalizador del proceso:

Social representations are developed and maintained within a culture through social influence. As people within the culture converse with each other, and as the media reports on events and present cultural information, these beliefs are shared and strengthened and become the important cultural norms. However, the principles of social influence might lead us to expect that, given enough time, the beliefs held by the members 
of a culture will become more and more homogeneous, and in the end there would be little variations in norms and beliefs among the individuals (Stangor, 2004, 273).

Como se puede apreciar, las diferentes corrientes siguen teniendo puntos de encuentro en sus enfoques. La interacción comunicativa, mediante cierto proceso de influencia, genera identificaciones en colectivos que van habituando las ideas y planteamientos en un acervo general que es institucionalizado en el marco general del conocimiento.

Esto queda mejor explicado en la Dynamic social impact theory, la cual asume que todas las creencias relevantes se encuentran disgregadas en la cultura gracias a que los individuos se comunican entre sí. Y para predecir la influencia social, se espera que con el tiempo el tamaño de la mayoría crezca y el de la minoría disminuya (Stangor).

Todos estos conocimientos generados y que, en apariencia, a ojos de nuestro entendimiento, siempre han estado allí, han ido construyéndose y evolucionando con el pasar del tiempo. Sandra Jovchelovitch lo explica al decir que las "Communities of people now must handle the diversity of realities that constitutes their life horizons and find new symbolics strategies to make sense of them (Jovchelovitch, 1997, Grervais \& Jovchelovitch, 1998). Some of these realities are utterly new, some are grounded in well-stablished traditions, and some belong to the merging of realities that takes place in highly mediated societies. In any case, sense is attained, sustained, and transformed in a manner that trascend the limitations traditionally imponed by context” (Deaux, y otros, 2001, 171).

Por ello, y a efectos de comprender nuestra contribución en el marco de la música más adelante, citamos una vez más a Burr haciendo alusión a los padres del construccionismo social: "Berger and Luckmann show how the world can be socially constructed by the social practices of people but at the same time experienced by them as if the nature of their world is pre-given an fixed" (Burr, 2003, 13). Aseveración importante sobremanera, pues más adelante entenderemos cómo los significados tácitos que otorgamos a la música han sido construidos desde épocas inmemoriales.

En contraposición a esto, y para finalizar nuestro repaso teórico, estudiaremos una corriente que defiende que los significados no son gestados en la interacción de colectivos sociales, sino que son éstos los que despiertan una referencia, latente hasta ese momento, en nuestra mente.

El planteamiento general del generativismo de Noam Chomsky parte de una interrogante de Russell que Chomsky visita en una de sus obras: “¿Cómo ocurre que seres humanos, cuyos contactos con el mundo son breves, personales y limitados, son capaces, sin embargo, de llegar a saber tanto como saben?" (Russell citado por Chomsky, 1979 ${ }^{\mathrm{a}}$ 14). 
Interrogante que el mismo Chomsky contesta: "Podemos llegar a saber tanto porque, en cierto sentido, ya lo sabíamos antes, aún si los datos de los sentidos fueron necesarios para despertar y dilucidar este saber, o, para decirlo menos paradójicamente, nuestros sistemas de creencias son aquellos para cuya construcción está proyectada nuestra mente, en tanto que estructura biológica” (Chomsky, 1979ª 17).

Es así como el autor se plantea la presencia innata en nosotros -sin origen en lo socialde aquellos elementos necesarios para desentrañar las estructuras significantes de todo fenómeno que trate de comunicar algo.

Haciendo alusión al pensamiento racional, propone que el ser humano posee ciertas cualidades "programadas", necesarias para interpretar los significados; menciona "nociones de relación" como "Causa y Efecto, Todo y Partes, Semejanzas y Desemejanzas, Proporción y Analogía, Igualdad y Desigualdad, Simetría y Asimetría”, y explica que todas ellas no son "huellas materiales impresas en el alma desde el exterior, sino su propia concepción activa procedente de sí misma al tiempo que toma conciencia de los objetos exteriores" (Chomsky, 1979ª 17).

Inicialmente, su obra, muy enfocada hacia la consolidación de una gramática generativa, estableció planteamientos sobre la semántica que dejaban entrever de manera matizada su visión sobre las "ideas innatas" o "nociones comunes". Al respecto citamos un pasaje en el que, luego de criticar lo concerniente a representación fonética, alude a la semántica: "Dudas todavía más fuertes pueden ser expresadas (y a menudo lo han sido) con respecto a la noción de representación semántica. Así, cabría argüir que las creencias no lingüísticas, las intenciones del hablante y otros factores entran en la interpretación de las expresiones de manera tan íntima (y quizás tan fluctuante e indefinida) que es inútil y desquiciado intentar representar independientemente el componente "puramente gramatical” del significado, las diversas "lecturas" de las expresiones en el sentido de Katz y Postal 1964 y otras versiones de la teoría común, y las relaciones entre estas lecturas y una estructura sintáctica” (Chomsky, 1979 $\left.{ }^{\mathrm{b}}, 79\right)$.

Según la perspectiva de Chomsky, existe un elemento innato en los individuos que trasciende lo social y que nos permite desarrollar nuestra interpretación personal de los contenidos semánticos de los discursos a los que nos sometemos día a día. Aunque esta visión es totalmente opuesta a la de los imaginarios colectivos (en la que nos hemos explayado), queremos presentarla aquí a manera de teoría complementaria, puesto que pretendemos más adelante explicar un asunto que ocurre en el ámbito musical y que alude a ambas dimensiones teóricas. 


\section{Lo musical y sus imaginarios colectivos}

Ahora bien, todo lo anteriormente expuesto como referencia teórica ha sido llevado al campo musical sólo de manera superficial. Incluso el actual escrito, aunque trata de establecer una guía completa en materia de semántica musical y de imaginarios colectivos musicales, no es más que la presentación de un panorama inicial.

Lo primero que cabría aclarar con respecto a la música es el problema que subyace al código. Cada vez se nos hace más familiar el término "comunicación musical" aunque no existan muchas formalizaciones al respecto. El hecho musical y su carácter comunicativo ha despertado el interés de antropólogos, sociólogos, psicólogos, comunicólogos y demás, citando una muestra muy pequeña de investigadores y teóricos.

En una investigación previa, en la que se trataba de instaurar un modelo esquemático para la comunicación musical, se encontró que existía, a nivel semántico, un código instituido que tenía un carácter denotativo (la notación musical) y un “código" (si se puede llamar así) que tenía un carácter altamente connotativo y que no poseía aún una formalización teórica suficiente como para poder ser planteado de manera explícita. En aquel entonces, se explicó con respecto al mensaje:

Indudablemente, ver el mensaje bajo la concepción limitada de la mayoría de los modelos comunicacionales puede tener consecuen- cias catastróficas, puesto que si tenemos dos niveles de emisión $y$, por ende, dos niveles de codificación y descodificación de mensaje, uno de ellos tiene un significado denotativo y el otro lo puede tener connotativo y contextual (el de la música). De hecho, la mayoría de las disertaciones en torno al significado de la música han terminado en discusiones acaloradas que no han llegado a un final del debate, y ésto radica principalmente en que no hay elementos semánticos instituidos para descodificar el mensaje musical. De hecho, parece haber un consenso en cuanto a la naturaleza del feed-back que se traduce en emociones, expresadas en torno a referentes o sentimientos (Borges y otros, 2006, 17).

Por ello, y para referirse con un poco más de libertad al asunto del "código" musical, se definirán de entrada dos términos: el de competencia y el de discurso. Para entrar en el terreno de lo que a competencia de refiere: "Después de varios artículos y discusiones autocríticas que sucedieron a la promulgación de su propuesta teórica, el propio Eco (1984 y 1990) terminó por reemplazar el concepto de código por otro más flexible, complejo y productivo: el de competencia” (López Cano, 2001).

Por su parte, Chomsky hace alusión en su obra al término competencia: "Hacemos, pues, una distinción fundamental entre COMPETENCIA (el conocimiento que el hablante-oyente tiene de su lengua) y ACTUACIÓN (el uso real de la lengua en 
situaciones concretas). Sólo en la idealización establecida en el párrafo anterior es la actuación reflejo directo de la competencia" (Chomsky, 1970, 6).

Así, si se le atribuye un carácter mucho más abierto a las estructuras de significación que median en el proceso de interpretación musical y se le otorga un rasgo más polivalente (al pasar de código musical a competencia musical) se puede entonces, en este plano exploratorio, trabajar sin formalismos técnicos y manejar abstracciones más ricas en contenidos. Sin más, se puede decir que la competencia musical es el conocimiento que el músico-audiencia tiene de la música en aras de su interpretación.

Pero esa música no posee características similares a las de la lengua. Para establecer una diferencia de peso, no existe una forma instituida de interpretación de las estructuras musicales luego de su audición. Por ello, y para seguir en la línea de tratamiento libre, se podría entender la música como una forma discursiva, tomando la acepción de discurso de Burr: "A discourse refers to a set of meanings, metaphors, representations, images, stories, statements, and so on, that in some way together produce a particular version of events" (Burr, 2003, 64).

La necesidad de establecer estas dos distinciones y remarcarlas (darle cualidades discursivas y de competencia a la música) se debe a que la música es un objeto de estudio con cualidades no sólo abstractas, sino muy ligadas al marco emocional humano. Ya Schopenhauer, Adorno y Platón subrayaban la forma en la que la música incide directamente en el alma de los hombres inflamando sus pasiones. Por ello, abordar un objeto de estudio de características tan incorpóreas con un formalismo exacerbado y un método riguroso podría arrojar resultados alejados de la realidad de estudio.

Por discurso musical se entienden aquellas estructuras sintácticas producidas por un ejecutante, aparato emisor, instrumento musical, etc., que trascienden más allá de la partitura y pueden ser interpretadas mediante la recepción. Éstas generan un estado anímico en la audiencia que las recibe por medio de su aparato auditivo y producen una respuesta.

Ya en el marco referencial se había hecho mención al discurso como parte fundamental de la construcción del conocimiento de los colectivos humanos, como una forma de catalizar los procesos de representación social y de facilitar la interacción social, pieza clave de la creación de imaginarios colectivos. Por ello, Burr complementa la idea al explicar que los "Discourses are not simple abstract ideas, ways of talking about and representing things that float like balloons far above the real world. Discourses are intimately connected to institutional and social practices that have a profound effect on how we live our lives, on what we can do and on what can be done to us" (Burr, 2003, 75). En consecuencia, se 
revisarán las formas de construcción social del sentido de las estructuras musicales.

Primero se explica de manera general y en palabras de Riego lo que implica el término imaginario en una de sus aserciones:

Las imágenes de la realidad difundidas masiva y repetitivamente van a colaborar en la construcción de un imaginario colectivo sobre la propia realidad. Entendiendo que el término imaginario es un concepto difuso y en definición en estos mismos momentos, podemos apuntar, tal y como lo hace Evelyne Patlageanm, que se trata del "conjunto de representaciones que desbordan el límite trazado por los testimonios de la experiencia y los encadenamientos deductivos que éstos autorizan. Lo que significa que cada cultura, y por tanto cada sociedad compleja, tiene su imaginario (Riego, 2001, 34).

Cook lo ambienta en el marco de lo musical haciendo alusión a lo que está determinado por la notación musical y lo que no:

También determina en gran medida cómo imaginan las personas la música en una cultura dada, y, de manera muy evidente, cómo conciben su música los compositores, aunque podría decirse que son modelos de imaginación compartidos los que mantienen unidos a todos los miembros de una cultura musical (Cook, 2003, 85).

Pousseur, además, comienza a explicar los elementos que influyen en la construcción de los imaginarios colectivos musicales:

Hemos llegado así a examinar la idea expuesta anteriormente que se refiere a una di- ferencia radical entre contenidos "extrínsecos" (es decir, consciente y voluntariamente referidos a realidades exteriores a la música) y contenidos "intrínsecos" (como, por ejemplo, un campo de impresiones, emociones y otros hechos psíquicos o imaginarios, exclusivamente reservados a la experiencia musical y que de ninguna manera parece que puedan ser traducidos a otro lenguaje) (Pousseur, 1984, 15).

La importancia del planteamiento de Pousseur recae en la diferenciación de los contenidos. En primer lugar, define los extrínsecos, donde se podrían agrupar todos los factores sociales y colectivos que influyen en el modelaje del "acervo común de conocimiento" y que han sido revisados por el construccionismo, la representación social y el interaccionismo simbólico; en segundo lugar, los contenidos intrínsecos, ya revisados por la visión particularista de Chomsky en su generativismo. De aquí parte todo.

Para poder explicar en profundidad estas dos dimensiones de la música se revisará inicialmente el aspecto social.

Anteriormente detallamos cómo se producen los procesos de institucionalización del conocimiento para construir la realidad, incluída la contemplación de varias corrientes teóricas así como los puntos de convergencia entre ellas. El primero que trataremos aquí será el de la interacción social.

En el caso de la música, la interacción también constituye la principal forma de crea- 
ción de habituaciones. A lo largo de muchos años de música, estas habituaciones se han creado no sólo en la composición (diferenciada superficialmente en cuanto a estilo y estética), sino en la forma de escuchar música $y$, por extensión, de comportarse ante ella. De hecho, el principal elemento que proporciona categorías a la música lo constituye las prácticas sociales: determinado tipo de música se emplea en determinada práctica social. Por tanto, determinada construcción discursiva (composición musical) está asociada a determinado uso social (De Aguilera, 2006).

Cook explica que “(...) el modo en que pensamos en la música también afecta al modo en que hacemos música, por lo que el proceso pasa a ser circular" (Cook, 2003, 85). Es así como la asociación entre las construcciones estilísticas y las prácticas va a condicionar las nuevas composiciones, las cuales, con el paso de los años, se institucionalizarán en conocimiento musical.

Cuando una determinada cadencia, modo, tonalidad o atonalidad, así como determinados ritmos, han sido utilizados con éxito por los autores para generar un estado emocional concreto en la audiencia, aquéllos pasan a formar parte de las tipificaciones y recetas que mencionaba Schutz y que formaban a la larga parte de nuestro acervo común. Indudablemente, los medios de comunicación de masas y las industrias culturales han ayudado a agilizar este proceso de institucionalización. Por ejemplo, las tonalidades menores se asocian con frecuencia a estados anímicos tristes y las tonalidades mayores a estados anímicos alegres. A pesar de que esto ha tratado de ser desmentido por músicos y académicos, Pousseur explica al respecto:

Si bien se ha adoptado la costumbre de considerar con el mayor escepticismo las afirmaciones asociativas que se refieren, por ejemplo, a los modos musicales y que relacionan (muy clásicamente) al modo menor con los sentimientos tristes y al modo mayor con las experiencias más luminosas o mucho más venerables (cfr. La República de Platón), cierta escala modal con los ambientes guerreros, cierta otra con los afectos lascivos, etc. Sin embargo, no se debería sonreír tan deprisa ni autorizarse para acusar a esta actitud de falta de convicción y de evidencia compartida (Pousseur, 1984, 16-17).

Si a veces se ha creído poder demostrar, por medio de constataciones en sentido contrario, el carácter "convencional" $y$, por tanto, no necesario de estas asociaciones, se debería tener en cuenta el hecho de que muy a menudo estos casos contrarios pueden ser utilizados para interferir a "otros" fenómenos. Por ejemplo, si hay una pieza en modo menor que, sin embargo, es alegre, ello es sin duda debido a que su ritmo ha obliterado, ha desviado en ese sentido (y sólo hasta cierto punto) las capacidades expresivas de su armonía (Pousseur, 1984, 17).

Cada utilización de la tesitura o el instrumento, de las tonalidades, los ritmos, las cadencias, las modulaciones, etc., constituye un elemento discursivo que ha conlleva- 
do un proceso de institucionalización con el paso de los años, un proceso en el que han participado simultáneamente audiencias y autores, y que en los primeros años se llevaba a cabo mediante interacciones en salas de conciertos $\mathrm{y}$, actualmente, a través de la difusión masiva de contenidos musicales a través de Internet, por citar un ejemplo.

Se vive una época en la que los medios de masas atribuyen a la música cualidades descriptivas (y por tanto semánticas) tan poderosas que despiertan respuestas difíciles de interpretar de manera distinta a la que cita la convencionalidad tácita y que es dictada por los imaginarios colectivos.

Cada sonido puede llegar a tener cualidades tangibles que han sido convenidas socialmente.

Al igual que las vibraciones luminosas, los sonidos nos aportan una imagen de las cosas, una información sobre algunas de sus propiedades: su peso, por ejemplo; su tensión, su elasticidad, la energía mecánica potencial que contienen y que pueden liberar en ciertas condiciones. Al hablarnos de su reacción a ciertos estímulos externos y también, una vez conocida esta reacción, de la naturaleza misma de estas fuerzas $y$ acciones de agitación, cada estructura sonora, cada sonido nos cuenta toda una pequeña historia, la cual está en relación de dependencia o de homeomorfia con muchas otras historias que podemos observar en otros niveles o en otros planos de realidad (Pousseur, 1984, 10).
En la actualidad y a un nivel macro, también los hábitos de escucha se convierten en discursos que las industrias culturales interpretan, condicionando la oferta musical (De Aguilera, 2006), de ahí que se establezcan convenciones estilísticas en las que las músicas populares son consumidas de manera masiva, mientras otras manifestaciones artísticas no lo son tanto. Las estrategias de comercialización bombardean el mercado de manera tan abrupta que la oferta y la demanda está generando cambios considerables en los imaginarios musicales y las institucionalizaciones discursivas están perdiendo riqueza; pero, en definitiva, esto pertenece a otro campo de estudio, que posee una fundamentación más profunda y extensa.

Para cerrar, se concluye que la interacción entre audiencias y autores legitima e institucionaliza estructuras discursivas, las cuales adecúan al tiempo que ejercitan las competencias musicales de los actores del proceso en un continuum que podríamos catalogar de acervo común de conocimiento,al estilo de Schutz, o Imaginario musical. Estos imaginarios son usados como marco referencial en el proceso de interpretación de los significados de las músicas empleadas en las prácticas sociales cotidianas. Indudablemente, éstos determinan las experiencias musicales sociales y, por tanto, refuerzan o actualizan los imaginarios colectivos y el marco semántico musical. De hecho: "Si uno se pregunta cuáles son las propiedades de una música que le 
permita representar, evocar, cierto campo de lo real (y que también le permita de forma eventual proponer seguidamente una elaboración original), pasa de una imitación relativamente literal en principio a analogías progresivamente metafóricas: se trata de instaurar relaciones análogas, con mayor claridad y de una forma gradual, en un medio más o menos diferente" (Pousseur, 1984, 15).

Cabría finalmente preguntarse si por medio de éstos imaginarios colectivos los actores se ajustan a contextos interpretativos dictaminados por sus fronteras culturales, al igual que ocurre con la lengua y los diferentes idiomas, o, por el contrario, la música trasciende las fronteras de la interpretación cultural.

Tal vez, la perspectiva generativa ofrezca alguna luz a este respecto. Storr, citando a Blacking, explica que "Los procesos psicológicos y cognitivos básicos que generan la composición y la interpretación musical pueden ser incluso herencias genéticas y, por tanto, estar presentes en casi todos los seres humanos" (Storr, 2002, 24).

Pousseur, tras plantear las dos perspectivas citadas con anterioridad, se decanta por la de las nociones preexistentes:

Llegamos así hasta el campo de las convicciones puramente arbitrarias, voluntaristas, que la educación y la costumbre pueden desde luego incrustar con bastante fuerza pero que, sin embargo, no tienen ninguna expresividad innata. De todos modos, me parece que lo específicamente musical se atiene muy raras veces a estas convenciones, y que casi siempre está apoyado en capacidades expresivas mucho más "naturales", dotadas de un porcentaje de eficacia mucho más alto. Yo, por mi parte, estoy convencido de que las bases de nuestra armonía tradicional, por ejemplo, con sus fuerzas de "atracción” y los poderes expresivos que de ellas resultan, están lejos de ser puras elaboraciones convencionales, y creo que radican en mecanismos de percepción muy imperativos. Por supuesto, se precisa una cierta educación para captar todo esto; $y$, por otra parte, la cultura no deja ni ha dejado nunca de reforzar, de acentuar de un modo sin duda considerable, estas potencialidades originales. Pero en cualquier caso estas virtualidades preexistían. La cultura no las ha inventado, en el sentido de haberlas sacado de la nada absoluta; simplemente las ha descubierto y las ha manifestado (Pousseur, 1984, 19).

La existencia de elementos innatos que permiten interpretar lo que la música pretende decir no es una teoría del todo descabellada, pues los estudios cognitivos han demostrado que los procesos relacionales que permiten hacer interpretaciones de otra índole son exactamente los mismos que permiten relacionar elementos inherentes a la música. "El análisis lingüístico distingue entre las características prosódicas del habla y las sintácticas: el acento, el tono, el volumen, el énfasis y cualquier otro rasgo que posea significado emocional por oposición a la estructura gramatical y al 
sentido literal. Existen numerosas similitudes entre la comunicación prosóica y la música" (Storr, 2002, 27).

De hecho, Dissanayake explica que "No importa la relevancia final del significado léxico gramatical; el cerebro humano está organizado o programado, en primera instancia, para responder a los aspectos emocionales y tonales de la voz humana" (Storr, 2002, 26).

Existen unidades sonoras mínimas que producen en nuestro organismo una respuesta psico-orgánica, en cuanto que el organismo humano, cuerpo acústico, no es indiferente ante los estímulos sonoros. Es decir, las frecuencias vibratorias tienen en los individuos un efecto que a nivel cognitivo es recibido e interpretado, y esta interpretación propende a una respuesta emocional.

Pousseur complementa esta idea:

Se sabe desde hace mucho tiempo que las propiedades armónicas están relacionadas con las proporciones (de frecuencia vibratoria, de ritmo microtemporal) que los diversos intervalos musicales establecen entre los sonidos o notas, y con la extraordinaria capacidad que posee nuestro aparato auditivo de captar estas propiedades bajo una forma sintética y cualitativa (del mismo modo que interpretamos en términos de color las diferentes frecuencias luminosas). Los grupos de intervalos, escalas, melodías, acordes, estructuras polifónicas, constituyen, pues, al ser proyectadas en el tiempo, verdaderas figuras proporcionales, a la vez geométricas y "coloreadas", y el hecho de que nuestra percepción auditiva admita ciertas aproximaciones no me parece que contradiga en nada esta evidencia. ¿No reconoce del mismo modo nuestro ojo el cuadrado o el círculo, incluso cuando su realización denota una cierta 'tosquedad'?" (Pousseur, 1984, 17).

Pousseur también plantea que la percepción del entramado armónico utiliza muy variadas categorías del entorno psicosomático del individuo. Este hecho de entendimiento particularmente elaborado (y que no afecta únicamente al aparato auditivo), es la clave de la cognición musical humana. Explica que la percepción anticipa los "contenidos" posibles de los movimientos sonoros a través de las "sensaciones" e incluso de los "sentimientos" que despiertan en el receptor (por el hecho de su acuerdo o desacuerdo con su estado más o menos constante).

La musicalidad intrínseca en el habla permite que se establezcan analogías con los elementos de acentuación, intensidad y énfasis de la música, que permiten (a nivel musical) despertar ciertos estados anímicos en la audiencia, tal y como Chomsky explicaba que los estímulos activaban ideas innatas y preexistentes.

Pousseur, en un pasaje de su obra Música, semántica y sociedad, hace alusión al carácter transcultural de la música y plantea que "Quedan por analizar en detalle los fundamentos de la expresividad armónica (que ha permitido que el público japonés asimile 
tan rápidamente la música de Beethoven o de Ravel, y que los occidentales nos atragantemos con ragas hindúes)" (Pousseur, 1984, 18). De hecho, Fernando Díez dedica todo un apartado de su obra El legado de la India a la música en la India, en el cual expone elementos teóricos, estéticos y filosóficos de la música. En la capítulo referente a la teoría musical (formalmente con un tratamiento mucho más espiritual) explica que en la tradición india existen doce notas al igual que en occidente, y cuenta una historia que envuelve de manera mística el carácter de cada una. En especial se retratan en este escrito dos muy particulares: Sa y Pa.

Sa es el equivalente occidental a un Do, con la única diferencia de que la afinación del Sa es particular de cada músico. Según Díez, Sa "evoca la tranquilidad y un estado de beatitud eterna" y $\mathrm{Pa}$ "es el aliado perfecto de Sa y siempre está en armonía con él. Es inalterable y da asilo a cualquier nota débil. Es digna, amable e iluminadora. Tiene la fuerza y la virtud de Sa, y su contenido emotivo irradia dignidad y heroísmo” (Díez, 2005, 280). En efecto, Pa es la nota atribuida a Sol. Esta alianza perfecta entre Sa y $\mathrm{Pa}$ nos remite por analogía a la consonancia perfecta de la quinta justa entre Do y Sol propia del sistema tonal occidental, lo que propone una obligada reflexión en torno al asunto del parcelamiento cultural tan arraigado y defendido por los colectivos sociales, y que parece perder fuerza ante una inminente globalización en proceso.

Tal vez exista un componente que tienda a lo orgánico y a lo psico-físico, tal y como lo explican Chomsky y Pousseur, y, a su vez, un constante refuerzo social, como lo plantea Cook. Lo más seguro es que en la construcción de un postulado complementario entre ambas teorías pueda llegarse a una conclusión tan polivalente como la música misma. En épocas antiguas, cuando la música era música y el hombre era hombre, lo importante era trascender a través de ella en rituales y prácticas sagradas que proporcionaban al espíritu el elixir revitalizante para seguir existiendo.

Al final, y en palabras de Stravinski: "Extraigo la conclusión de que los elementos tonales se transforman en música sólo en virtud de su organización y que tal organización presupone un acto humano consciente" (Storr, 2002, 23), y es finalmente la consciencia humana la que permitirá comprender la música más allá de su carácter etéreo y trascendente, perseverando en la sinceridad de espíritu de la audiencia. 


\section{Conclusiones}

Luego de confrontar dos líneas teóricas en apariencia contrapuestas, se reafirma la postura unificadora que puede arrojar cierta luz al fenómeno de la construcción de sentido en la música.

Esa doble dimensión que la música posee en el marco de su significación plantea todo un reto a la hora de teorizar el fenómeno, y se decanta entre dos modelos teóricos:

1. En una memoria colectiva inherente a la condición humana y que según las teorías generativistas son patrones de interpretación que poseemos desde el nacimiento.

2. En la corriente construccionista, basamento para la creación de imaginarios sociales - en nuestro caso musicales por medio de la interacción de colectivos sociales y que son acervos de experiencias, conocimientos, ideas, etc. que retratan de alguna manera nuestra realidad.

En el esquema lineal del proceso de comunicación musical, partiendo del eje de la creación, pareciera que no es el autor o la industria la que se encarga de producir sentido, son todos los actores involucrados en el proceso comunicativo musical (autor, productor, audiencias, etc.) los que producen el sentido. Incluso, se podría decir que el sentido es atribuido por la cultura o por el imaginario en sí al que recuren los individuos para comprender el discurso musical.

Sustentados en esta afirmación podríamos alegar que el proceso de atribución ocurre mayormente al momento de la escucha y no al momento de la composición, lo que no quiere decir necesariamente que el autor no tenga una cuota de responsabilidad en la forma en la que se comprende el discurso musical. Para comprender esto, partiremos de la premisa inicial de que el autor, tomando en cuenta tácita o explícitamente los valores y subjetividades que conforman el imaginario musical de un colectivo con el que comparte ciertas prácticas sociales, configura un discurso musical para que al momento de la escucha la experiencia musical exista afinidad con la audiencia.

\section{Referencias}

Berger, P. y Luckmann, T. (1993) La construcción social de la realidad. Amorrourtu Editores. Buenos Aires, Argentina.

Borges, Pérez y Valenzuela (2006) Modelo teórico de comunicación musical: Actualización y fundamentación. Comunicación para las XIII Jornadas de jóvenes investigadores en Comunicación: Nuevos retos de la comunicación: tecnología, empresa y sociedad. Zaragoza, España.

Burr, V. (2003) Social Constructionism. Routledge. Hove, East Sussex, UK

Camero Rioja, M. (2002) Interacción social y desarrollo moral. El género y las formas de adhesión a los valores. 
Servicio de Publicaciones e Intercambio Científico de la Universidad de Málaga. Málaga. España.

Chomsky, N. (1970) Aspectos de la teoría de la sintaxis. Aguilar Ediciones. Madrid, España.

Chomsky, N. (1979 ) Reflexiones sobre el lenguaje. Ariel. Barcelona, España.

Chomsky, N. (1979 $)$ Sintáctica y semántica de la gramática generativa. Siglo veintiuno editores. Madrid, España.

Cook, N. (2003) De Madonna al canto gregoriano. Una muy breve introducción a la música. Alianza Editorial. Madrid, España

De Aguilera, M. (2006) Seminario de Música y Comunicación: Una perspectiva de estudio, del Programa de Doctorado en Comunicación y Música de la Universidad de Málaga.

Deaux, K. y Philogëne, G. (2001) Representations of the Social. Blackwell Publishers. Oxford, UK.

Díez, F. (2005). El legado de la India. Mandala Ediciones. Madrid, España.
Dijk, T A van (1997) El discurso como estructura y proceso. Gedisa. Barcelona.

López, R. (2001). Entre el giro lingüistico y el guiño hermenéutico: tópicos y competencia en la semiótica musical actual. Seminario de Semiología Musical. Universidad de Valladolid, Conferencia. Disponible http: / / www.geocities.com/lopezcano/Publicacion es on line.html Fecha de consulta: 12 de junio de $\underline{2008}$

Mugny, G. y Doise, W. (1983) La construcción social de la inteligencia. Editorial Trillas. D.F., México.

Pousseur, H. (1984) Música, semántica, sociedad. Alianza Editorial. Madrid, España.

Riego, B. (2001) La construcción social de la realidad a través de la fotografía y el grabado informativo en la España del siglo XIX. Servicio de Publicaciones de la Universidad de Cantabria. España.

Stangor, C. (2004) Social Groups in Action and Interaction. Psychology Press. New York, U.S.A.

Storr, A. (2002) La música y la mente. El fenómeno auditivo y el porqué de las pasiones. Ediciones Paidós Ibérica. Barcelona, España.

Cita de este artículo

Borges Rey, Eddy L. (2009) Imaginario colectivo musical. Convenciones en el proceso de interpretación del sentido de la música. Revista Icono14 [en línea] 25 de Octubre de 2009, № 14. pp. 210-231. Recuperado (Fecha de acceso), de http://www.icono14.net 